\title{
A dependence modelling study of extreme rainfall in Madeira Island
}

\author{
Délia Gouveia-Reis a, b, c, *, Luiz Guerreiro Lopes c, d, e, 1 , Sandra Mendonça a, b \\ ${ }^{a}$ Faculty of Exact Sciences and Engineering, University of Madeira, Penteada Campus, 9000-390 Funchal, Madeira Is., Portugal \\ ${ }^{\mathrm{b}}$ CEAUL - Center of Statistics and Applications, University of Lisbon, Campo Grande, 1749-016 Lisbon, Portugal \\ ${ }^{c}$ CIMO - Mountain Research Centre, ESA/IPB, 5300-253 Bragança, Portugal \\ d ICAAM - Institute of Mediterranean Agricultural and Environmental Sciences, University of Évora, Mitra Campus, 7002-554 Évora, Portugal \\ e PPG-CLIAMB - INPA/UEA and RHASA - Laboratory for Water Resources and Satellite Altimetry, Amazonas State University, 69050-020 Manaus, AM, Brazil
}

\section{A R T I C L E I N F O}

\section{Article history:}

Received 3 March 2015

Received in revised form 30 October 2015

Accepted 12 November 2015

Available online 2 December 2015

\section{Keywords:}

Statistics of extremes

Kendall's tau

Copula functions

Extreme rainfall

\begin{abstract}
A B S T R A C T
The dependence between variables plays a central role in multivariate extremes. In this paper, spatial dependence of Madeira Island's rainfall data is addressed within an extreme value copula approach through an analysis of maximum annual data. The impact of altitude, slope orientation, distance between rain gauge stations and distance from the stations to the sea are investigated for two different periods of time. The results obtained highlight the influence of the island's complex topography on the spatial distribution of extreme rainfall in Madeira Island.
\end{abstract}

(c) 2015 Elsevier Ltd. All rights reserved.

\section{Introduction}

In mountainous regions, such as the high, steep mountains and deep valleys of Madeira Island, extreme rainfall can trigger flash floods (Spreafico, 2006), landslides and debris flows (Kalvoda and Rosenfeld, 1998; Rodrigues and Ayala-Caicedo, 2003), particularly during the wet season. Although rare, such events can have significant impacts on the local natural environment and disastrous consequences for the affected communities and populations (Woo and Jones, 2002). Rainfall-induced debris flows are one of the most dangerous natural hazards in mountain regions (Hu et al., 2009), because their occurrence is unpredictable and this type of waterrelated natural disaster can be catastrophic, affecting significantly not only the landscape, but also causing damage to houses and infrastructures (Kanji et al., 2008), loss of lives (Wilford et al., 2004), and other negative economic and social impacts due to the increasing anthropisation of such areas (Hürlimann et al., 2006). Floods and associated landslides and debris-flows triggered by extreme rainfall events have been in reality the most devastating of

\footnotetext{
* Corresponding author. Faculty of Exact Sciences and Engineering, University of Madeira, Penteada Campus, 9000-390 Funchal, Madeira Is., Portugal.

E-mail addresses: delia@uma.pt (D. Gouveia-Reis), lopes@uma.pt (L. Guerreiro Lopes),smfm@uma.pt (S. Mendonça).

${ }^{1}$ On sabbatical leave from the University of Madeira, Funchal, Portugal.
}

natural disasters, both in Madeira Island (Baioni, 2011; Quintal, 1999) as in the rest of the world (Hong et al., 2007).

Madeira Island has in its history a significant number of rainfallinduced flash floods, landslides and debris flows. The first event of this nature described in the literature occurred in November 1724 , which caused the death of 26 people and serious damage to 80 houses in the city of Machico, and damages to buildings in Santa Cruz and Funchal. In the following century, more precisely in October 1803, Madeira suffered its worst calamity, a flash flood with approximately six hundred deaths and a huge devastation in Funchal. Other southern areas like Machico, Santa Cruz, Campanário, Ribeira Brava and Calheta were also affected by this devastating event. In the last century, six catastrophic rainfallinduced events were registered in Madeira, namely in 1920, 1929, 1956, 1979, 1993 and 1997, totaling more than 60 deaths and several dozens of injured people and houses destroyed (see, e.g., Baioni, 2011; Fragoso et al., 2012; Quintal, 1999). More recently, already in the 21st century, two significant events of this type were registered in Madeira Island, the first in March 2001, with five deaths and material damages of several tens of million euros (Rodrigues and Ayala-Caicedo, 2003), and the second one in February 2010, which caused 45 casualties, six missed people, more than a hundred injured and about 1.4 billion euros of material losses (Baioni, 2011; Fragoso et al., 2012), which indicate an increase in the frequency of such events and in the damage caused by them. 
This emphasize the need for appropriate statistical models of extreme hydrological events, particularly in the current context of global and regional climate and environmental changes, since the modelling of extreme rainfall has an important role in the design of water-related structures, in rural and agricultural engineering, and in many other areas, such as civil defense, where the hydrological monitoring and the knowledge concerning weather and climate extremes are fundamental. However, in many mountain regions, such as Madeira Island, the lack of sufficiently long series of rainfall data at different time scales leads to the challenge of estimating statistical characteristics of extreme rainfall from relatively short records (Koutsoyiannis, 2004). Moreover, in mountainous areas, the rainfall distribution is strongly influenced by factors such as the topography and the direction and intensity of wind, which make local and spatial analysis of the available data a difficult topic. This is clearly the case in Madeira Island, where the exact distribution of rainfall is strongly dependent upon the complex topography and the prevailing winds during the rain events, and where the estimation of hydro-meteorological extremes continues to be highly uncertain.

A review of spatial extremes methods based on latent variables, copulas and spatial max-stable processes was presented by Davison et al. (2012), who refer that appropriately chosen copula or maxstable models seem to be essential for the modelling of spatial extremes. The ability to describe and model the dependence between variables, regardless of their marginal distribution functions, is the major advantage of the copula functions approach. In practice, the application of these functions to the data can be considered based on an estimate of a measure of association, such as the Kendall's $\tau$ (Nelsen, 2006; Salvadori et al., 2007). A survey on the relationships between concordance of random variables and their copulas was made by Nelsen (2002), focusing on the relationship between concordance and measures of association such as Kendall's $\tau$, Spearman's $\rho$, and Gini's coefficient. The two first measures, Kendall's $\tau$ and Spearman's $\rho$, play an important role in applications, since the practical fit of a copula to the available data is often carried out via the estimation of these values. In fact, according to Salvadori et al. (2007), Kendall's $\tau$ and Spearman's $\rho$ are the two most widely known and used scale-invariant measures.

In this paper, a study of the dependence between extreme rainfall values from 12 rain gauge stations distributed over Madeira Island was carried out based on the Kendall's $\tau$ association measure (Genest and Favre, 2007). An adjustment was also made to a family of extreme value copulas and return period estimates for a given extreme event were obtained. The structure of this paper is as follows. The study area and the available rainfall data used are described in Section 2, while the methodology applied in this study is described in Section 3. This is followed by Section 4, where the results of the analysis are presented and discussed. Finally, Section 5 contains a summary of the main findings and some final comments.

\section{Study area and data}

\subsection{Study area}

Madeira Island is a volcanic island located in the Atlantic Ocean off the coast of Northwest Africa, between latitudes $32^{\circ} 30^{\prime} \mathrm{N}-33^{\circ} 30^{\prime} \mathrm{N}$ and longitudes $16^{\circ} 30^{\prime} \mathrm{W}-17^{\circ} 30^{\prime} \mathrm{W}$. Madeira is $57 \mathrm{~km}$ long and $22 \mathrm{~km}$ wide and has an area of approximately $737 \mathrm{~km}^{2}$ (Gorricha et al., 2012). The island has a near E-W oriented orographic barrier, approximately perpendicular to the prevailing $\mathrm{N}-\mathrm{SE}$ wind direction, which induces a remarkable variation of rainfall between the northern and southern slopes (Fragoso et al., 2012). Madeira Island's mountain ridge located along its central part presents Pico Ruivo, the highest peak with $1861 \mathrm{~m}$, and Pico do Areeiro, with $1818 \mathrm{~m}$, in its eastern part, while Paul da Serra massif is located above $1400 \mathrm{~m}$ in the western part of the island.

The spatial distribution of rainfall in Madeira Island is strongly affected by its highly rugged topography, characterized by deep valleys and high and steep mountains, with $90 \%$ of the island's surface lying above $500 \mathrm{~m}$, and one third above $1000 \mathrm{~m}$ (Sziemer, 2000). The amount of rainfall increases with altitude and the northern slopes are more humid than the southern ones (Prada et al., 2009). Madeira's location, topography and natural vegetation originate a variety of micro-climates, and this Portuguese island has essentially a Mediterranean climate with mild summers and winters (Couto et al., 2012). Some exceptions are found at the highest altitudes, where the mean annual air temperature can decrease to $8^{\circ} \mathrm{C}$, while in the coastal regions it ranges between $18^{\circ}$ $\mathrm{C}$ and $19^{\circ} \mathrm{C}$ (Lima and Lima, 2009).

The rainfall regime over the island is not only affected by local air circulation, but also by synoptic systems typical of mid-latitudes such as fronts and extra-tropical cyclones. During the summer season, the rainfall regime is also affected by the Azores anticyclone (Couto et al., 2012). The island's mountain streams have a high seasonal, torrential flow regime, with high waters during the months of October to March/April (Shahin, 2012) and very low flows during the rest of the year.

\subsection{Rainfall data}

Relatively to Madeira's rainfall data records, it is known that the oldest weather station in Madeira, the one from Funchal, started to operate in January 1865 and that only in November 1936 another weather station located in Pico do Areeiro began to collect rainfall and temperature data. In order to provide useful information for agriculture, more weather stations were settled on the island from 1936 to 1955 , at different altitudes, by the General Council of the Autonomous District of Funchal (JGDAF). However, in 1990, some stations would no longer be functioning, others would provide data only concerning to the prevailing wind direction and intensity and other stations ceased to be maintained by JGDAF. Nowadays Madeira Island is covered by rain gauge stations maintained by three different institutions, namely the Madeira's Investments and Water Management (IGA) company, the Portuguese Institute for Sea and Atmosphere (IPMA), and the Madeira Regional Laboratory of Civil Engineering (LREC) (Fragoso et al., 2012). As referred before, the data used in this study correspond to maximum annual rainfall records from 12 rain gauge stations distributed over the island. Two measurement periods were considered for comparison purposes, being the record values corresponding to the period 1970-1994 (hereafter Period 1) provided by IPMA and those corresponding to the period 1950-1980 (hereafter Period 2) by the Department of Hydraulics and Energy Technologies of LREC. The rain gauge stations are distributed by four altitude classes, termed as Class 1 (>900 m), $2(600-900 \mathrm{~m}), 3(300-599 \mathrm{~m})$ and $4(<300 \mathrm{~m})$, in descending order of altitude (A to L), and represented in Fig. 1 by different marker colours (in the web version), namely green, yellow, orange and red, respectively. Besides the six stations from Period 1 (Areeiro, Bica da Cana, Santo da Serra, Santana, Funchal and Lugar de Baixo), six more stations are considered in Period 2: one from Class 1 (Montado do Pereiro), three from Class 2 (Ribeiro Frio, Queimadas and Camacha), one from Class 3 (Sanatório), and one from Class 4 (Ponta Delgada). The altitude class, identification name and ID label for each rain gauge station, as well as the altitude and the slope where each one of these stations is located are indicated in Table 1 , where $\mathrm{N}$ denotes the northern slope and $\mathrm{S}$ the southern one. 


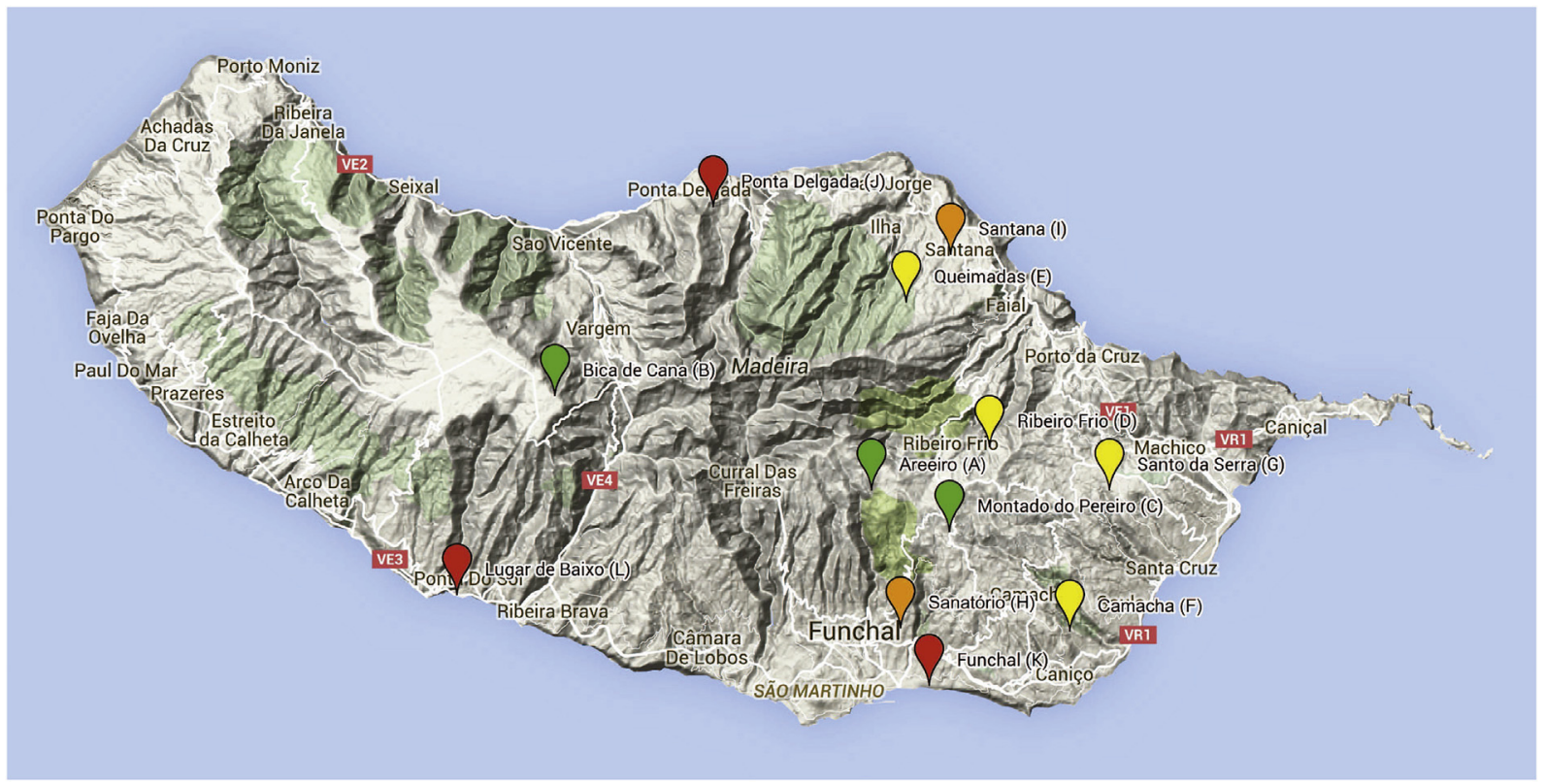

Fig. 1. Location and altitude range of the rain gauge stations used in this study (map data@Google).

Table 1

Details of the rain gauge stations.

\begin{tabular}{llllll}
\hline Class & Station name (ID) & Latitude & Longitude & Alt. (m) & Slope \\
\hline 1 & Areeiro (A) & $32^{\circ} 43^{\prime} \mathrm{N}$ & $16^{\circ} 55^{\prime} \mathrm{W}$ & 1610 & $\mathrm{~S}$ \\
& Bica da Cana (B) & $32^{\circ} 45^{\prime} \mathrm{N}$ & $17^{\circ} 03^{\prime} \mathrm{W}$ & 1560 & $\mathrm{~N}$ \\
\multirow{4}{*}{2} & Montado do Pereiro (C) & $32^{\circ} 42^{\prime} \mathrm{N}$ & $16^{\circ} 53^{\prime} \mathrm{W}$ & 1260 & $\mathrm{~S}$ \\
& Ribeiro Frio (D) & $32^{\circ} 43^{\prime} \mathrm{N}$ & $16^{\circ} 53^{\prime} \mathrm{W}$ & 874 & $\mathrm{~S}$ \\
& Queimadas (E) & $32^{\circ} 46^{\prime} \mathrm{N}$ & $16^{\circ} 54^{\prime} \mathrm{W}$ & 860 & $\mathrm{~N}$ \\
& Camacha (F) & $32^{\circ} 40^{\prime} \mathrm{N}$ & $16^{\circ} 50^{\prime} \mathrm{W}$ & 680 & $\mathrm{~S}$ \\
\multirow{3}{*}{3} & Santo da Serra (G) & $32^{\circ} 43^{\prime} \mathrm{N}$ & $16^{\circ} 49^{\prime} \mathrm{W}$ & 660 & $\mathrm{~S}$ \\
& Sanatório (H) & $32^{\circ} 39^{\prime} \mathrm{N}$ & $16^{\circ} 54^{\prime} \mathrm{W}$ & 380 & $\mathrm{~S}$ \\
& Santana (I) & $32^{\circ} 48^{\prime} \mathrm{N}$ & $16^{\circ} 53^{\prime} \mathrm{W}$ & 380 & $\mathrm{~N}$ \\
& Ponta Delgada (J) & $32^{\circ} 49^{\prime} \mathrm{N}$ & $16^{\circ} 59^{\prime} \mathrm{W}$ & 136 & $\mathrm{~N}$ \\
& Funchal (K) & $32^{\circ} 38^{\prime} \mathrm{N}$ & $16^{\circ} 53^{\prime} \mathrm{W}$ & 58 & $\mathrm{~S}$ \\
& Lugar de Baixo (L) & $32^{\circ} 40^{\prime} \mathrm{N}$ & $17^{\circ} 05^{\prime} \mathrm{W}$ & 15 & $\mathrm{~S}$ \\
\hline
\end{tabular}

\section{Methodology}

The concept of copula function was introduced by Sklar's theorem (Sklar, 1959), who established that, if $n \geq 2$ is a natural number and $\left(X_{1}, \ldots, X_{n}\right)$ a random vector with continuous marginal probability distribution functions $F_{1}, \ldots, F_{n}$ and joint probability distribution function $H$, then there is a unique function $C$ such that the joint probability distribution function $H$ can be written for $x_{1}, \ldots, x_{n} \in \mathbb{R}$ as

$$
H\left(x_{1}, \ldots, x_{n}\right)=C\left(F_{1}\left(x_{1}\right), \ldots, F_{n}\left(x_{n}\right)\right) .
$$

Special examples of copula functions are the Fréchet-Hoeffding upper bound copula defined, for $u=\left(u_{1}, \ldots, u_{l}\right) \in \mathbb{q}^{l}$, with $\mathbb{\square}=[0,1]$ and $l \geq 2$, by $M_{l}(u)=\min \left(u_{1}, \ldots, u_{l}\right)$, and the product copula defined by $\Pi_{l}(u)=u_{1} \ldots u_{l}$. Because the variables $X_{1}, \ldots, X_{n}$ are independent if and only if the corresponding copula is $\Pi_{n}$ (Nelsen, 2006), this copula is also called the independence copula (Salvadori et al., 2007).

According to Nelsen (2002), many of the ways to describe and measure dependence between random variables remain unchanged under strictly increasing transformations of these ones. The concordance is one of these scale-invariant dependence forms. On the other hand, it is also known (cf., e.g., Schweizer and Wolf
(1981)) that the copula functions capture the properties of dependence between random variables. A known statistical test of independence (Genest and Favre, 2007), for $l=2$, is based on the empirical version of Kendall's $\tau$ measure, that can be defined by

$\tau_{n}=\frac{c-d}{c+d}=\frac{4 c}{n(n-1)}-1$,

where $c$ and $d$ represent the number of concordant and discordant pairs, respectively, in a sample of size $n$ from a pair of continuous random variables $(X, Y)$. Under the null hypothesis $H_{0}: C=\Pi_{2}$ of independence between $X$ and $Y$, the distribution of $\tau_{n}$ can be approximated by the normal distribution with zero mean and variance $2(2 n+5) / 9 n(n-1)$. Thus, $H_{0}$ would be rejected, for example, at the significance level of 0.05 , if

$\sqrt{\frac{9 n(n-1)}{2(2 n+5)}}\left|\tau_{n}\right|>1.96$

A family of copulas of particular interest when modelling extreme values is the family of extreme value copulas. An extreme value $l$-copula $C^{*}$, with $l \geq 2$, can be defined as a copula satisfying the equality

$C^{*}\left(u_{1}^{t}, \ldots, u_{l}^{t}\right)=\left(C^{*}\right)^{t}\left(u_{1}, \ldots, u_{l}\right)$,

for all $t>0$. The Fréchet-Hoeffding upper bound and the product copulas are examples of such type of copulas. Another example of an extreme value copula (EVC) is the weighted geometric mean of these two copulas, known as the Cuadras-Augé family of copulas, whose members are given by $C_{\theta}(u)=\Pi_{l}^{1-\theta}(u) M_{l}^{\theta}(u)$, where $\theta \in \square$. More generally, if $A$ and $B$ are $l-E V C$, then

$C_{\alpha_{1}, \ldots, \alpha_{l}}(u)=A\left(u_{1}^{\alpha_{1}}, \ldots, u_{l}^{\alpha_{l}}\right) B\left(u_{1}^{1-\alpha_{1}}, \ldots, u_{l}^{1-\alpha_{l}}\right)$

defines a family of $l-$ EVC with parameters $\alpha_{1}, \ldots, \alpha_{l} \in \mathbb{0}$. This fact allows the construction of a more versatile family of extreme value copulas. For example, taking $l=3, A=C_{\theta}$ and $B=\Pi_{l}$, the $l$-copula given by 
$C^{*}\left(u_{1}, u_{2}, u_{3}\right)=\Pi_{i=1}^{3} u_{i}^{1-\beta_{i}} \min \left(u_{1}^{\beta_{1}}, u_{2}^{\beta_{2}}, u_{3}^{\beta_{3}}\right)$

where $\beta_{i}=\theta \alpha_{i} \in \llbracket$ is a $l-E V C$. The estimation of the parameters $\beta_{1}$, $\beta_{2}$ and $\beta_{3}$ from the extreme value copula $C^{*}$ can be made using the estimated values of Kendall's $\tau$ for the several pairs of random variables and the relation

$\frac{1}{\beta_{i}}=\frac{1}{2}\left(1+\frac{1}{\tau^{i, j}}+\frac{1}{\tau^{i, k}}-\frac{1}{\tau^{j, k}}\right)$,

where $(i, j, k)$ is a permutation of $(1,2,3)$ (Salvadori et al., 2007).

These relationships allow the estimation of the probability of extremal events. In practice, given a random vector $\left(X_{1}, \ldots, X_{n}\right)$, an event is here defined as extreme if one or more variables exceed some given high values. Of particular practical interest is the event

$E_{q}=E_{3}^{X_{1, q}, X_{2, q}, X_{3, q}}=\left\{X_{1}>x_{1, q}, X_{2}>x_{2, q}, X_{3}>x_{3, q}\right\}$,

where $X_{i}$ denotes the observation at the $i-$ th rain gauge station and $x_{i, q}$ the $(1-q)-$ quantile of $X_{i}$ for $q \in(0,1)$ and $i \in\{1,2,3\}$. The return period $r_{q}$ of $E_{q}$ is given by $1 / p_{q}$, with

$$
\begin{aligned}
p_{q} & =P\left(E_{q}\right) \\
& =1-3 q-C^{*}(q, q, q)+C^{*}(q, q, 1)+C^{*}(q, 1, q)+C^{*}(1, q, q) .
\end{aligned}
$$

In a first stage, for each pair $(X, Y)$, where $X$ and $Y$ correspond to the annual maxima dataset obtained in the stations identified by the same labels, the independence was analysed through the application of the statistical test referred before in this section. So, for all the pairs formed by the stations considered in each period $i$ ( $i \in 1,2$ ), the estimates of Kendall's $\tau$ association measure, $\tau_{n_{i}, Y}^{X,}$, and the $p$-values for the independence tests were determined through the use of the VINECOPULA package of $R$ language ( $R$ Development Core Team, 2011).

In a second stage of this study, groups formed by three pairwise associated stations were found and the estimated values of Kendall's $\tau$ measure of association from each pair were used to determine the coefficients $\beta_{1}, \beta_{2}$ and $\beta_{3}$ of the extreme value copula $C^{*}$. Then, for $q=0.98$ and $q=0.99$, the probability $p_{q}=P\left(E_{q}\right)$ and the corresponding return period $r_{q}=1 / p_{q}$ were calculated for each one of those groups.

\section{Results and discussion}

Table 2 shows the values of $\tau_{n_{1}}^{X, Y}$ above the corresponding $p$-values in brackets when Period 1 is considered. The pairs of associated stations found in this period are displayed in Fig. 2, while the corresponding groups of three pairwise associated stations obtained are presented in Table 3. The highest value for $\tau_{n}$ corresponds to the pair formed by Santo da Serra $(G)$ and Lugar de Baixo (L) stations $\left(\tau_{n_{1}}^{G, L}=0.49\right)$, which belong to different classes of altitude and are located at very different distances of the sea. The same happens with the pair of stations with the second highest value of $\tau_{n}\left(\tau_{n_{1}}^{G, I}=0.40\right)$, Santo da Serra (G) and Santana (I), although these two stations present a smaller difference in terms of altitude and distance. The pair formed by Santo da Serra (G) and Santana (I), located respectively in the southern and northern parts of the island, even shows a higher value of $\tau_{n_{1}}$ than that presented by the pair formed by Santana (I) and other northern station, namely Bica da Cana (B).

Bica da Cana (B), Santo da Serra (G), Santana (I) and Lugar de Baixo (L) rain gauge stations form three of the four groups of three pairwise associated stations found in Period 1, identified in
Table 2

Kendall's $\tau$ estimates and $p$-values (in brackets) for Period 1 (Statistically significant concordances are boldfaced).

\begin{tabular}{llllll}
\hline & $\mathrm{B}$ & $\mathrm{G}$ & $\mathrm{I}$ & $\mathrm{K}$ & $\mathrm{L}$ \\
\hline $\mathrm{A}$ & 0.04 & $\mathbf{0 . 2 5}$ & 0.14 & $\mathbf{0 . 2 7}$ & $\mathbf{0 . 3 3}$ \\
& $(0.77)$ & $(\mathbf{0 . 0 5})$ & $(0.28)$ & $(\mathbf{0 . 0 3})$ & $(\mathbf{0 . 0 1})$ \\
$\mathrm{B}$ & & $\mathbf{0 . 2 9}$ & $\mathbf{0 . 3 5}$ & $\mathbf{0 . 3 3}$ & $\mathbf{0 . 2 5}$ \\
& & $(\mathbf{0 . 0 2})$ & $(\mathbf{0 . 0 0})$ & $(\mathbf{0 . 0 1})$ & $(\mathbf{0 . 0 5})$ \\
$\mathrm{G}$ & & $\mathbf{0 . 4 0}$ & 0.15 & $\mathbf{0 . 4 9}$ \\
& & & $(\mathbf{0 . 0 0})$ & $(0.23)$ & $(\mathbf{0 . 0 0})$ \\
$\mathrm{I}$ & & & 0.15 & $\mathbf{0 . 3 2}$ \\
& & & & $(0.23)$ & $(\mathbf{0 . 0 1})$ \\
$\mathrm{K}$ & & & & 0.12 \\
& & & & & $(0.33)$ \\
\hline
\end{tabular}

Table 3. It can be observed that the lowest and highest return periods were obtained for the groups including the pair $B-G$, and the pair G-L belongs to the two groups with the highest return period values. Besides Santana $(G)$ and Lugar de Baixo (L), the group with the second highest return periods also includes Areeiro (A) and is the unique group formed solely by southern stations. The only two northern rain gauge stations considered in Period 1, Bica da Cana (B) and Santana (I), show a statistically significant concordance in this period that is not observed in Period 2. The values of $\tau_{n_{2}}^{X, Y}$ and the corresponding $p$-values found in this last period for the stations which belong to the group of common stations to both periods (hereafter Group 1) are displayed in Table 4.

Like in Period 1, the hypothesis of independence is also rejected in Period 2, at a 0.05 significance level, for the three pairs of stations B-G, G-I and I-L. These pairs show lower Kendall's $\tau$ empirical values than those presented by the two remaining pairs of stations common to both periods, whose independences were rejected in Period 2, namely $\mathrm{I}-\mathrm{K}$ and $\mathrm{K}-\mathrm{L}$. These pairs present the particularity of not forming pairs of pairwise associated stations in Period 1. Even more, it was observed that Santana (I) station forms with Funchal $(\mathrm{K})$ station the pair that presents the higher Kendall's $\tau$ empirical value in Period 2. Despite their proximity to the sea, Santana (I) and Funchal (K) are located in different slopes and the distance between them is higher than that between Santana (I) and Ponta Delgada (J) stations, which present a much smaller value of $\tau_{n_{2}}$ (see Table 6). Santana (I) forms with Funchal (K) and Lugar de Baixo (L) a group of pairwise associated southern stations observed only in Period 2. On the other hand, none of the groups of three pairwise associated stations observed in Period 1 were found in Period 2. Therefore, the study of Period 2, a shorter period with an earlier beginning than Period 1, allowed the observation of the loss, gain, and also maintenance of concordance for some pairs of stations along the time.

In Period 2, a better coverage of Madeira Island was naturally obtained by an increase of the number of rain gauge stations, which allowed the observation of more groups of three pairwise associated stations. The values of $\tau_{n_{2}}^{X, Y}$ and the corresponding $p$-values found for Montado do Pereiro (C), Ribeiro Frio (D), Queimadas (E), Camacha (F), Sanatório (H) and Ponta Delgada (J) (group of stations referred hereafter as Group 2) are displayed in Table 5.

Table 6 shows that, in Period 2, Areeiro (A) forms groups of pairwise associated stations with the southern stations Montado do Pereiro (C) and Camacha (F), and also with the northern stations Queimadas (E) and Ponta Delgada (J). The obtained groups and the 


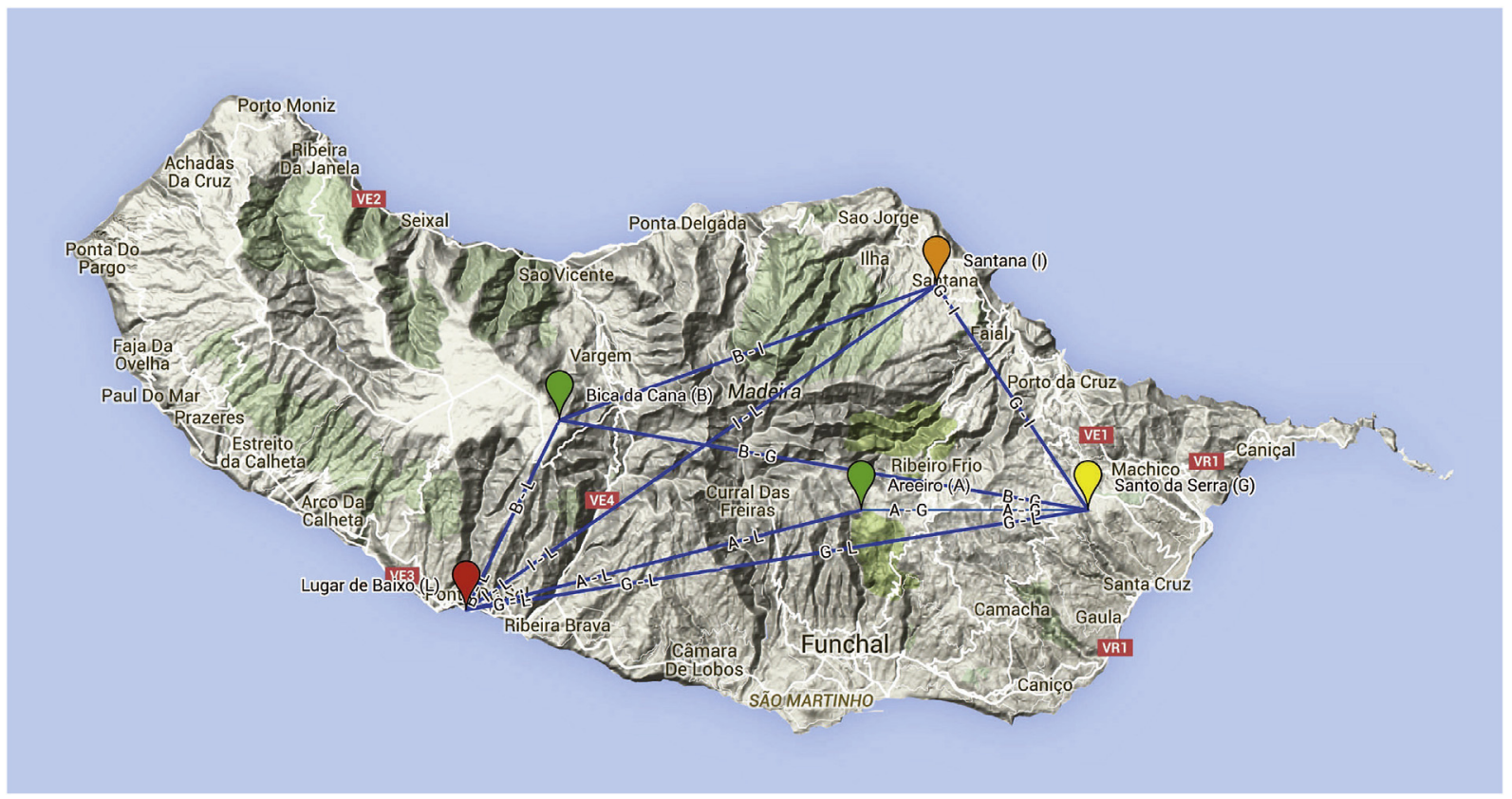

Fig. 2. Triplets of pairwise associated stations for Period 1 (map data@Google).

Table 3

Triplets and corresponding parameters and return period estimates for Period 1 .

\begin{tabular}{llllll}
\hline Group & $\beta_{1}$ & $\beta_{2}$ & $\beta_{3}$ & $r_{0.98}$ & $r_{0.99}$ \\
\hline A-G-L & 0.334 & 0.499 & 0.966 & 147.74 & 297.50 \\
B-G-I & 0.416 & 0.489 & 0.688 & 119.17 & 239.31 \\
B-G-L & 0.312 & 0.804 & 0.557 & 157.38 & 317.58 \\
B-I-L & 0.423 & 0.671 & 0.380 & 130.65 & 262.35 \\
\hline
\end{tabular}

Table 4

Kendall's $\tau$ estimates and $p$-values in brackets with stations of Group 1 for Period 2 (Statistically significant concordances are boldfaced).

\begin{tabular}{llllll}
\hline & $\mathrm{B}$ & $\mathrm{G}$ & $\mathrm{I}$ & $\mathrm{K}$ & $\mathrm{L}$ \\
\hline $\mathrm{A}$ & 0.04 & -0.02 & 0.19 & 0.16 & 0.16 \\
& $(0.77)$ & $(0.91)$ & $(0.13)$ & $(0.21)$ & $(0.21)$ \\
$\mathrm{B}$ & & $\mathbf{0 . 2 9}$ & 0.22 & 0.27 & 0.23 \\
& & $(\mathbf{0 . 0 2})$ & $(0.09)$ & $(0.07)$ & $(0.06)$ \\
$\mathrm{G}$ & & $\mathbf{0 . 2 9}$ & 0.23 & 0.20 \\
& & & $(\mathbf{0 . 0 2})$ & $(0.06)$ & $(0.11)$ \\
$\mathrm{I}$ & & & $\mathbf{0 . 5 4}$ & $\mathbf{0 . 4 0}$ \\
& & & & $(\mathbf{0 . 0 0})$ & $\mathbf{( 0 . 0 0 )}$ \\
$\mathrm{K}$ & & & & $\mathbf{0 . 4 2}$ \\
& & & & & $(\mathbf{0 . 0 0})$ \\
\hline
\end{tabular}

Table 5

Kendall's $\tau$ estimates and $p$-values in brackets with stations of Group 2 for Period 2 (Statistically significant concordances are boldfaced).

\begin{tabular}{llllll}
\hline & $\mathrm{D}$ & $\mathrm{E}$ & $\mathrm{F}$ & $\mathrm{H}$ & $\mathrm{J}$ \\
\hline $\mathrm{C}$ & $\mathbf{0 . 4 0}$ & 0.15 & $\mathbf{0 . 4 9}$ & $\mathbf{0 . 3 7}$ & $\mathbf{0 . 3 8}$ \\
& $(\mathbf{0 . 0 0})$ & $(0.23)$ & $(\mathbf{0 . 0 0})$ & $(\mathbf{0 . 0 0})$ & $(\mathbf{0 . 0 0})$ \\
$\mathrm{D}$ & & 0.15 & $\mathbf{0 . 3 2}$ & $\mathbf{0 . 2 7}$ & 0.20 \\
& & $(0.23)$ & $(\mathbf{0 . 0 1})$ & $(\mathbf{0 . 0 3})$ & $(0.12)$ \\
$\mathrm{E}$ & & $\mathbf{0 . 1 2}$ & 0.11 & $\mathbf{0 . 3 2}$ \\
& & $(0.33)$ & $(0.37)$ & $(\mathbf{0 . 0 1})$ \\
$\mathrm{F}$ & & & $\mathbf{0 . 4 5}$ & $\mathbf{0 . 2 9}$ \\
& & & & $(\mathbf{0 . 0 0})$ & $(\mathbf{0 . 0 2})$ \\
$\mathrm{H}$ & & & & $\mathbf{0 . 2 5}$ \\
& & & & & $(\mathbf{0 . 0 5})$ \\
\hline
\end{tabular}

Table 6

Kendall's $\tau$ estimates and $p$-values (in brackets) for stations in Group 1 with the ones in Group 2 for Period 2 (Statistically significant concordances are boldfaced).

\begin{tabular}{lllllll}
\hline & $\mathrm{C}$ & $\mathrm{D}$ & $\mathrm{E}$ & $\mathrm{F}$ & $\mathrm{H}$ & $\mathrm{J}$ \\
\hline $\mathrm{A}$ & $\mathbf{0 . 2 5}(\mathbf{0 . 0 5})$ & $0.14(0.28)$ & $\mathbf{0 . 2 7}(\mathbf{0 . 0 3})$ & $\mathbf{0 . 3 3}(\mathbf{0 . 0 1})$ & $0.06(0.62)$ & $\mathbf{0 . 2 9}(\mathbf{0 . 0 2})$ \\
$\mathrm{B}$ & $\mathbf{0 . 2 9}(\mathbf{0 . 0 2})$ & $\mathbf{0 . 3 5}(\mathbf{0 . 0 0})$ & $\mathbf{0 . 3 3}(\mathbf{0 . 0 1})$ & $\mathbf{0 . 2 5}(\mathbf{0 . 0 5})$ & $0.16(0.21)$ & $\mathbf{0 . 2 9}(\mathbf{0 . 0 3})$ \\
$\mathrm{G}$ & $\mathbf{0 . 3 5 ( 0 . 0 1 )}$ & $0.18(0.16)$ & $\mathbf{0 . 2 8}(\mathbf{0 . 0 3})$ & $\mathbf{0 . 3 6}(\mathbf{0 . 0 0})$ & $\mathbf{0 . 3 1}(\mathbf{0 . 0 1})$ & $\mathbf{0 . 2 5}(\mathbf{0 . 0 5})$ \\
$\mathrm{I}$ & $0.18(0.16)$ & $0.14(0.28)$ & $0.18(0.15)$ & $\mathbf{0 . 2 5}(\mathbf{0 . 0 5})$ & $\mathbf{0 . 2 5}(\mathbf{0 . 0 5})$ & $\mathbf{0 . 3 1}(\mathbf{0 . 0 1})$ \\
$\mathrm{K}$ & $\mathbf{0 . 3 2}(\mathbf{0 . 0 1})$ & $0.23(0.07)$ & $0.06(0.62)$ & $\mathbf{0 . 4 2}(\mathbf{0 . 0 0})$ & $\mathbf{0 . 5 1}(\mathbf{0 . 0 0})$ & $0.23(0.07)$ \\
$\mathrm{L}$ & $\mathbf{0 . 3 8}(\mathbf{0 . 0 0})$ & $\mathbf{0 . 2 6}(\mathbf{0 . 0 4})$ & $0.03(0.83)$ & $\mathbf{0 . 4 3}(\mathbf{0 . 0 0})$ & $\mathbf{0 . 3 9}(\mathbf{0 . 0 0})$ & $\mathbf{0 . 3 3}(\mathbf{0 . 0 1})$ \\
\hline
\end{tabular}

corresponding estimates for the parameters and return periods are displayed in Table 7. Here, the group that presents the lowest return periods $(\mathrm{A}-\mathrm{F}-\mathrm{J})$ includes two stations located in different classes of altitude and opposite slopes. The pairs of the groups of three pairwise associated stations found in this period are displayed in Fig. 3.

Like Areeiro (A), Bica da Cana (B) and Santo da Serra (G) stations are also in concordance with Montado do Pereiro (C), Queimadas (E), Camacha $(\mathrm{F})$ and Ponta Delgada $(\mathrm{J})$ in Period 2. The resulting pairs are represented in Fig. 4 and the obtained groups of three pairwise associated stations are displayed in Table 8. The group that presents here the highest return periods includes the pair $B-G$ and Camacha (F), the southernmost station among the mentioned four stations. The remaining three groups present similar return period estimates.

The inclusion in Period 2 of the northern stations Queimadas (E) and Ponta Delgada (J) originates the only group of three northern

Table 7

Triplets including Areeiro (A) and corresponding parameters and return period estimates for Period 2.

\begin{tabular}{llllll}
\hline Group & $\beta_{1}$ & $\beta_{2}$ & $\beta_{3}$ & $r_{0.98}$ & $r_{0.99}$ \\
\hline A-C-F & 0.334 & 0.499 & 0.966 & 147.74 & 297.50 \\
A-C-J & 0.345 & 0.478 & 0.649 & 143.71 & 289.15 \\
A-E-J & 0.398 & 0.457 & 0.517 & 124.66 & 250.33 \\
A-F-J & 0.496 & 0.496 & 0.411 & 120.62 & 242.29 \\
\hline
\end{tabular}




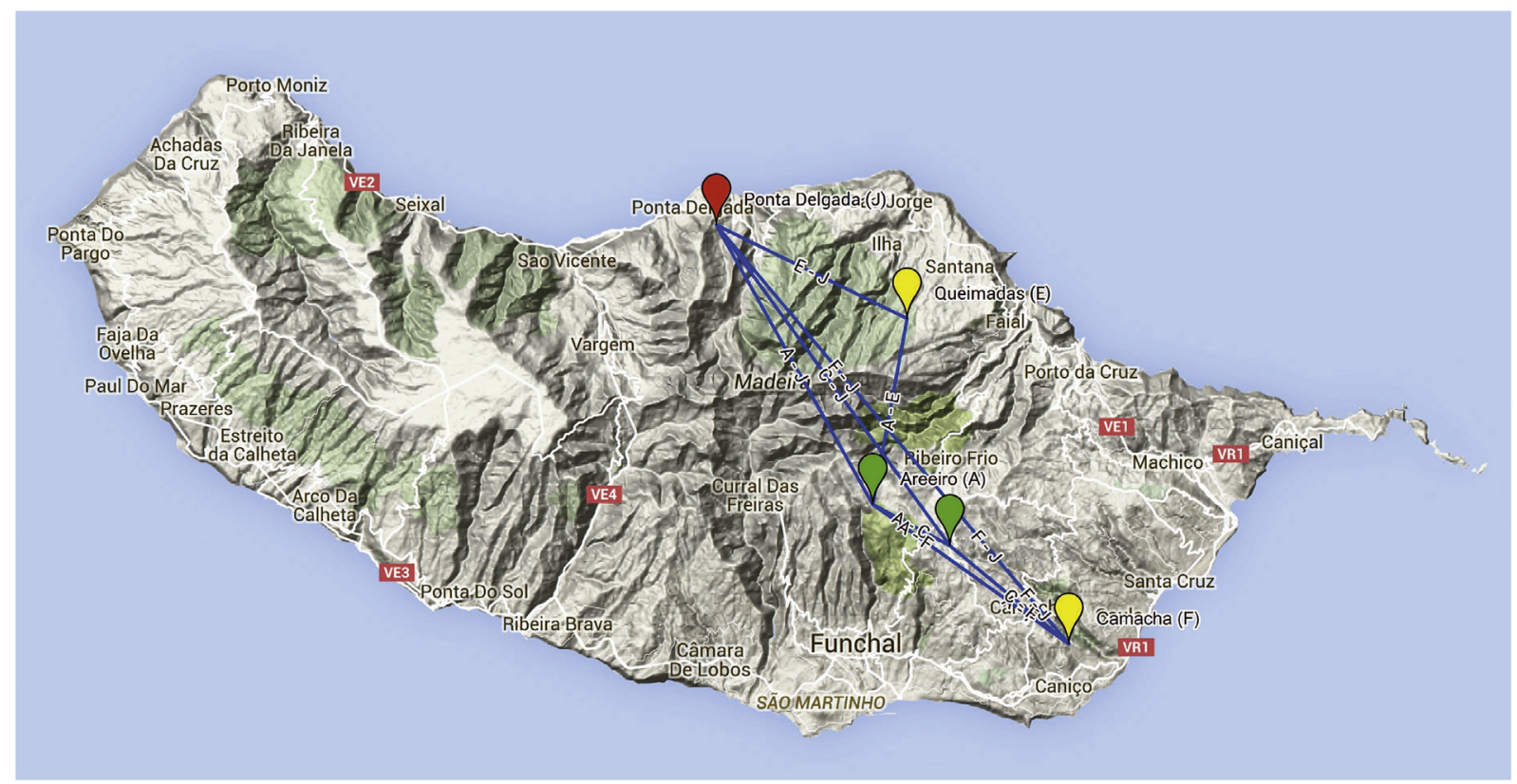

Fig. 3. Triplets of associated stations including Areeiro (A) for Period 2 (map data@Google).

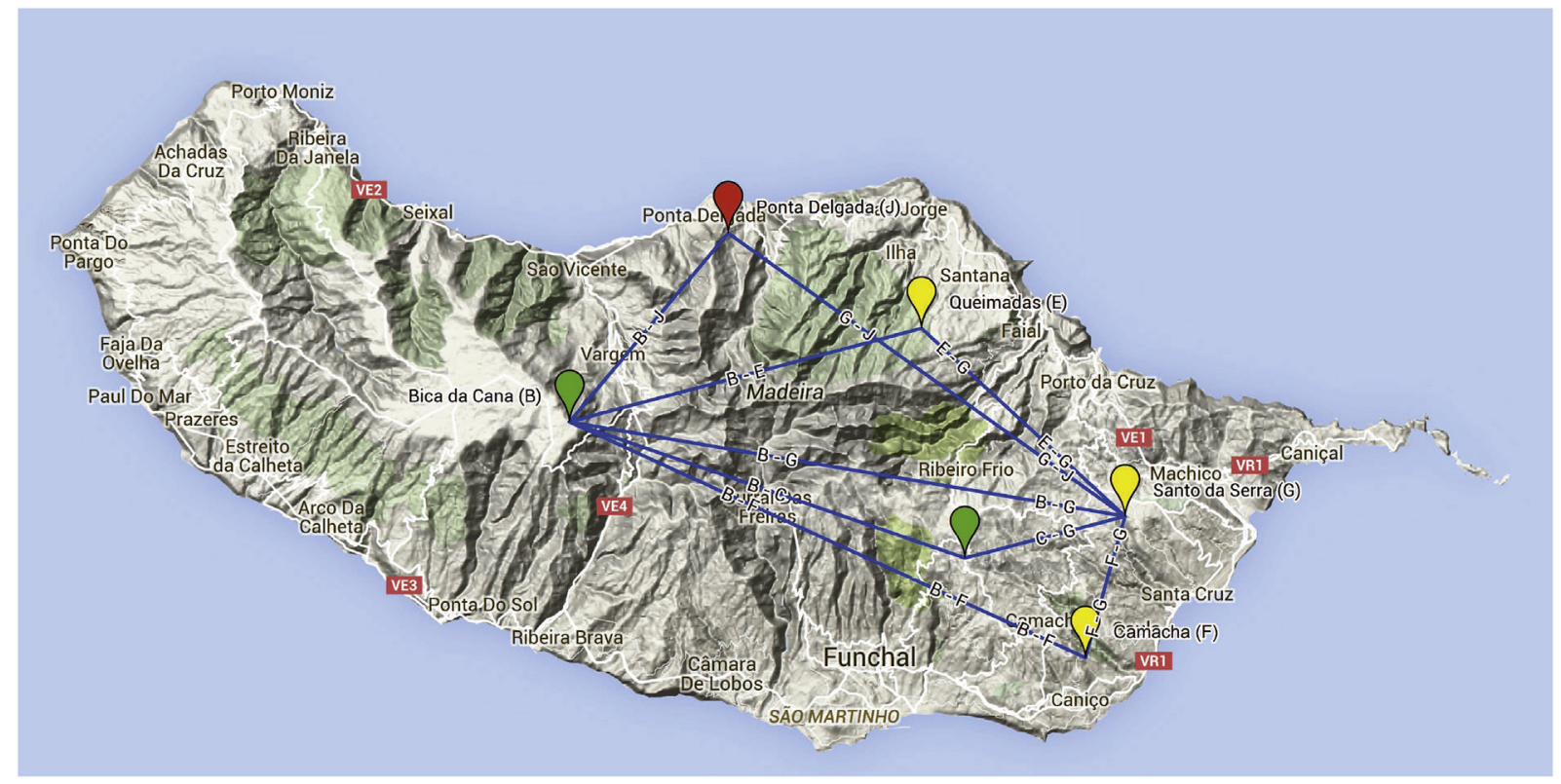

Fig. 4. Pair $B-G$ and other associated stations for Period 2 (map data@Google).

Table 8

Triplets including pair $\mathrm{B}-\mathrm{G}$ and corresponding parameters and return period estimates for Period 2.

\begin{tabular}{llllll}
\hline Group & $\beta_{1}$ & $\beta_{2}$ & $\beta_{3}$ & $r_{0.98}$ & $r_{0.99}$ \\
\hline B-G-C & 0.397 & 0.519 & 0.519 & 124.74 & 250.72 \\
B-G-E & 0.512 & 0.482 & 0.401 & 123.68 & 248.44 \\
B-G-F & 0.353 & 0.462 & 0.620 & 140.25 & 282.03 \\
B-G-J & 0.513 & 0.400 & 0.400 & 124.22 & 249.23 \\
\hline
\end{tabular}

pairwise associated stations obtained in this study. This group, formed by these two stations and Bica da Cana (B), presents parameter estimates given by $\beta_{1}=0.459, \beta_{2}=0.540$ and $\beta_{3}=0.440$.
The obtained return period estimates $\left(r_{0.98}=112.87\right.$ and $\left.r_{0.99}=226.47\right)$ are lower than those for all the groups observed that include Bica da Cana (B). Contrary to Queimadas (E) station, Ponta Delgada $(\mathrm{J})$ is in concordance with the northern station Santana (I) as with the southern stations Montado do Pereiro (C) and Camacha (F). With these two last stations, Ponta Delgada (J) forms a group with the values $\beta_{1}=0.899, \beta_{2}=0.519$ and $\beta_{3}=0.397$ for the parameters estimates and return periods similar to those presented by the group $\mathrm{B}-\mathrm{G}-\mathrm{C}\left(r_{0.98}=124.74\right.$ and $\left.r_{0.99}=250.72\right)$. Camacha (F) is also included in the group shown in Table 9 that presents the higher return period estimates. The other two stations are the southern stations Santo da Serra (G) and Santana (I) which, on the other hand, are in concordance with the northern station Ponta 
Table 9

Triplets including pairs $\mathrm{G}-\mathrm{I}, \mathrm{I}-\mathrm{L}$ and corresponding parameters and return period estimates for Period 2.

\begin{tabular}{llllll}
\hline Group & $\beta_{1}$ & $\beta_{2}$ & $\beta_{3}$ & $r_{0.98}$ & $r_{0.99}$ \\
\hline G-I-F & 0.620 & 0.353 & 0.462 & 140.25 & 282.03 \\
G-I-H & 0.544 & 0.419 & 0.383 & 129.56 & 260.13 \\
G-I-J & 0.383 & 0.544 & 0.419 & 129.56 & 260.13 \\
I-K-L & 0.673 & 0.732 & 0.496 & 99.85 & 200.58 \\
\hline
\end{tabular}

Delgada (J) and the southern station Sanatório $(\mathrm{H})$. The two resulting groups of pairwise associated stations with similar return period estimates, and other two groups, $\mathrm{G}-\mathrm{I}-\mathrm{F}$ and $\mathrm{I}-\mathrm{K}-\mathrm{L}$, are represented in Fig. 5. The group with the lowest return period estimates among the groups observed in this figure is $\mathrm{I}-\mathrm{K}-\mathrm{L}$, which includes two southern stations ( $\mathrm{K}$ and $\mathrm{L}$ ) from Class 4 that are located in a different altitude class and in the opposite slope of the third one (I).

The pairs $\mathrm{I}-\mathrm{K}$ and $\mathrm{K}-\mathrm{L}$ form, with the southern stations Montado do Pereiro $(\mathrm{C})$, Camacha $(\mathrm{F})$ and Sanatório $(\mathrm{H})$, the pairs of associated stations represented in Fig. 6 included in the five groups of three pairwise stations presented in Table 10. These three southern stations form with the northern station Ponta Delgada $(\mathrm{J})$ two groups of pairwise associated stations. The group $\mathrm{F}-\mathrm{H}-\mathrm{J}$ presents the highest estimated values for the return periods $\left(r_{0.98}=153.23\right.$ and $\left.r_{0.99}=308.89\right)$ observed in Period 2 and the second highest values when both periods are considered. The parameters estimates for this group formed by stations from Classes 2 , 3 and 4 are $\beta_{1}=0.749, \beta_{2}=0.530$ and $\beta_{3}=0.321$ while the other group presents the values $\beta_{1}=0.856, \beta_{2}=0.394$ and $\beta_{3}=0.406$. Instead of the station belonging to Class 4 , the group $\mathrm{C}-\mathrm{H}-\mathrm{J}$ includes Montado do Pereiro (C), which belongs to Class 1 . This group presents lower return period estimates than the previous group $\left(r_{0.98}=125.93\right.$ and $\left.r_{0.99}=252.72\right)$. The southern stations in Class 4 , Funchal (K) and Lugar de Baixo (L), form with Camacha (F) the group with the lowest estimates for the return periods observed in this study. Although Camacha (F) and Funchal (K) are located at very different altitudes, they are closer to each other than to Lugar de Baixo (L). This group presents lower estimates than those presented by the group $\mathrm{K}-\mathrm{L}-\mathrm{H}$ although Funchal $(\mathrm{K})$ is located closer to Sanatório $(\mathrm{H})$ than to Camacha $(\mathrm{F})$.

Also the group formed by the pair Sanatório $(\mathrm{H})$ and Camacha (F) with the station Montado do Pereiro (C) presents lower return period estimates $\left(r_{0.98}=96.53\right.$ and $\left.r_{0.99}=193.64\right)$ than those presented by the group $\mathrm{K}-\mathrm{L}-\mathrm{H}$. This group, formed by Sanatório $(\mathrm{H})$ with two stations located in Classes 1 and $2, \mathrm{C}-\mathrm{F}-\mathrm{H}$, is a group with parameters estimates given by $\beta_{1}=0.568, \beta_{2}=0.781$ and $\beta_{3}=0.515$. The pairs that form this group are displayed in Fig. 7. It can be observed that each station of the pair $\mathrm{H}-\mathrm{L}$ forms with the stations in pair $\mathrm{D}-\mathrm{F}$ the two groups with the highest return periods among that displayed in Table 11. Both Ribeiro Frio (D) and Camacha (F) stations belong to Class 2 and form with Montado do Pereiro (C) another group of three pairwise associated stations. This group presents lower return period estimates than those presented by the group formed by the pair $\mathrm{C}-\mathrm{F}$ and Areeiro (A) station, in Class 1, although located in a higher altitude than Montado do Pereiro (C) (see Table 7). All the four southern stations included in Period 2 are associated with each other (cf. Table 5).

\section{Conclusion}

In this paper, a study was made on the dependence between extreme rainfall values from the considered stations based on Kendall's $\tau$ measure. The results obtained in this study suggest that special attention should be given to different factors in the spatial distribution of extreme rainfall in Madeira Island, including the altitude, the distance between stations, the slope where they are located, and the proximity to the sea, but also suggest that such a characterization can not be totally explained by those factors.

In some cases, the altitude and the distance to the sea may have a higher influence in the association between stations than the distance factor. For instance, in Period 2, Santo da Serra (G) and Sanatório $(\mathrm{H})$ show a higher Kendall's $\tau$ estimated value than the pair formed by Areeiro (A) and Montado do Pereiro (C). The latter stations are nearly $3500 \mathrm{~m}$ far from each other, and the distance between Santo da Serra $(G)$ and Sanatório $(H)$ is approximately

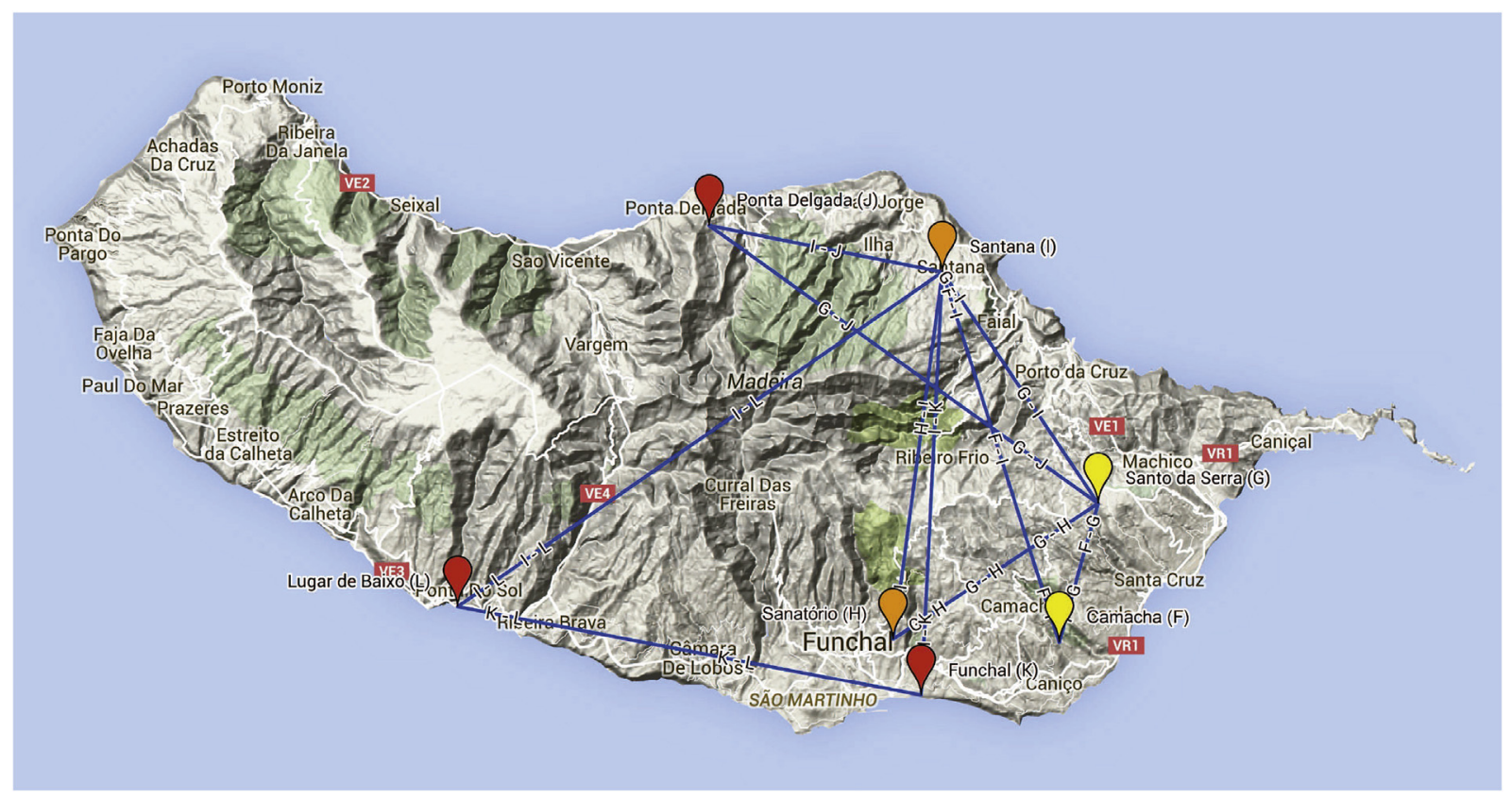

Fig. 5. Pairs G-I and I-L and other associated stations for Period 2 (map data@Google). 


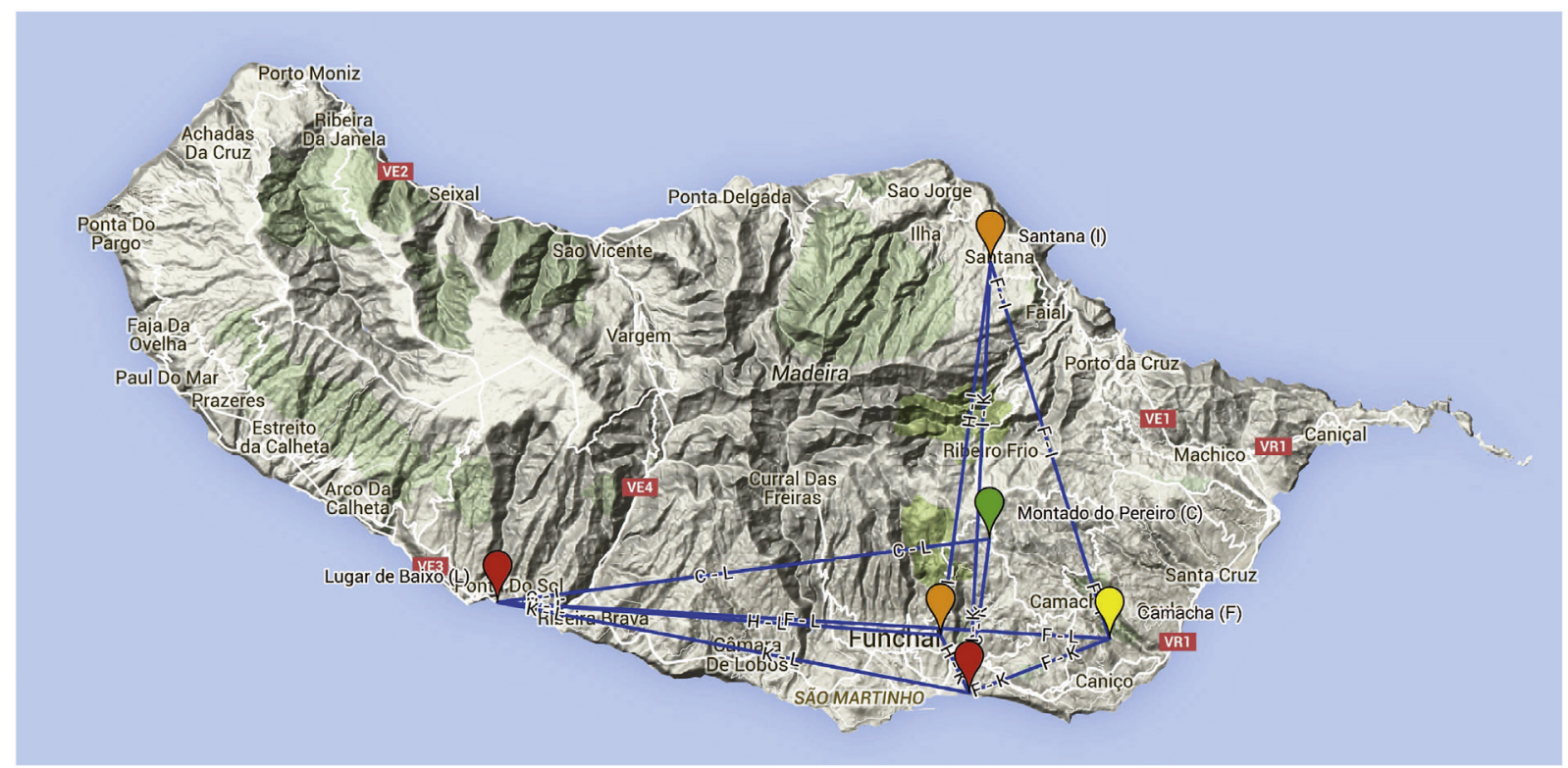

Fig. 6. Pairs $\mathrm{I}-\mathrm{K}$ and $\mathrm{K}-\mathrm{L}$ and other associated stations for Period 2 (map data@Google).

Table 10

Triplets including pairs $\mathrm{I}-\mathrm{K}$ and $\mathrm{K}-\mathrm{L}$ and corresponding parameters and return period estimates for Period 2.

\begin{tabular}{llllll}
\hline Group & $\beta_{1}$ & $\beta_{2}$ & $\beta_{3}$ & \multicolumn{1}{l}{$r_{0.98}$} & $r_{0.99}$ \\
\hline I-K-F & 0.447 & 0.362 & 0.447 & 136.91 & 275.16 \\
I-K-H & 0.409 & 0.392 & 0.409 & 126.84 & 254.57 \\
K-L-C & 0.457 & 0.516 & 0.693 & 108.62 & 218.02 \\
K-L-F & 0.601 & 0.582 & 0.601 & 85.52 & 171.44 \\
K-L-H & 0.636 & 0.720 & 0.502 & 98.84 & 198.44 \\
\hline
\end{tabular}

Table 11

Triplets including pairs $\mathrm{C}-\mathrm{D}$ and $\mathrm{D}-\mathrm{F}$ and corresponding parameters and return period estimates for Period 2.

\begin{tabular}{llllll}
\hline Group & $\beta_{1}$ & $\beta_{2}$ & $\beta_{3}$ & $r_{0.98}$ & $r_{0.99}$ \\
\hline C-D-F & 0.828 & 0.436 & 0.546 & 113.62 & 228.22 \\
C-D-H & 0.800 & 0.444 & 0.408 & 121.79 & 244.47 \\
C-D-L & 0.875 & 0.424 & 0.402 & 123.59 & 248.04 \\
D-F-H & 0.357 & 0.757 & 0.526 & 138.40 & 278.58 \\
D-F-L & 0.354 & 0.768 & 0.494 & 139.47 & 280.61 \\
\hline
\end{tabular}

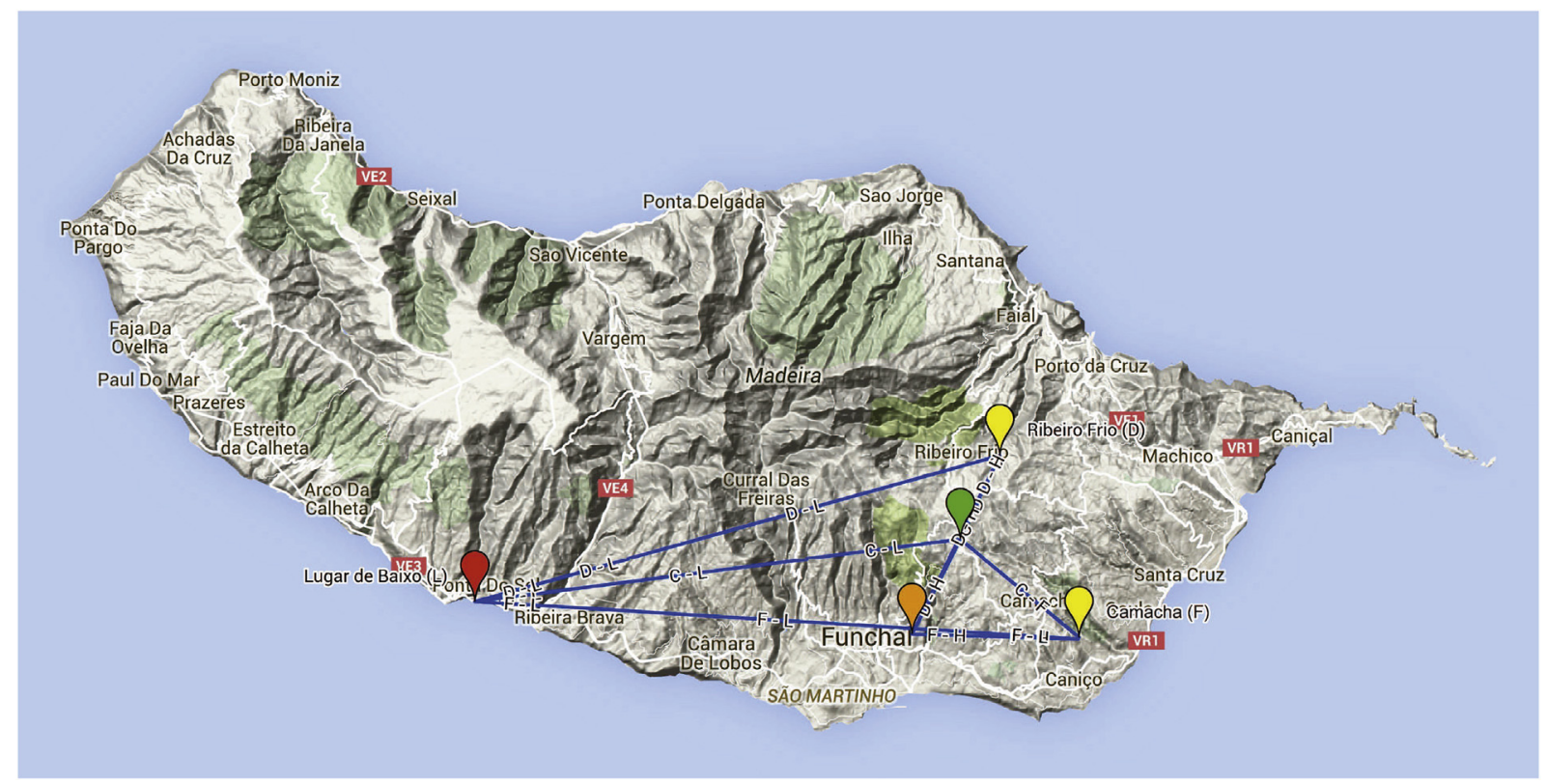

Fig. 7. Pairs $C-D$ and D-F and other associated stations for Period 2 (map data@Google).

$10750 \mathrm{~m}$. The justification for the higher value for the pair $\mathrm{G}-\mathrm{H}$, when compared to the corresponding value for the pair $\mathrm{A}-\mathrm{C}$, may be related to the fact that the association between rainfall and altitude tends to be more pronounced at the stations less exposed than those that are facing the sea (see, e.g., Hayward and Clarke (1996)).

Furthermore, greater exposure and proximity to the sea (or other large bodies of water) are more related with intense rainfall events 
(see, e.g., Konrad II (1996)), which may also contribute to the observed extreme rainfall at stations $\mathrm{G}$ and $\mathrm{H}$ to be less discrepant from each other than the maximum annual rainfall data recorded at the stations $\mathrm{A}$ and $\mathrm{C}$. This may also be an important factor for the existence of the association observed in Period 2 between Santana (I) station and each station of the pair Funchal (K) and Lugar de Baixo (L), which are also located near the sea but in the opposite slope.

However, it were also observed associated stations located in opposite slopes and altitudes with different distances from the sea which are distant from each other. For example, the independence is rejected for the pair formed by Montado do Pereiro (C) and Ponta Delgada (J) stations, that are approximately $15800 \mathrm{~m}$ apart. While Ponta Delgada $(\mathrm{J})$, on the north slope of the island, is located near the sea at an altitude of $136 \mathrm{~m}$, Montado do Pereiro (C) station is located on the lee side of the central mountainous region of Madeira Island at an altitude of $1260 \mathrm{~m}$.

The insufficiency of the mentioned factors for a complete characterization of the spatial distribution of extreme rainfall in Madeira Island is also observed in Period 1. For example, the highest value for the Kendall's $\tau$ estimate corresponds to the pair formed by Santo da Serra (G) and Lugar de Baixo (L) stations, which are far apart, belong to different classes of altitude and are located at different distances of the sea. Also the group with the lowest return periods observed in this period is formed by the northern stations Bica da Cana (B) and Santana (I) with the southern station Lugar de Baixo (L), located near the sea and in the lowest altitude considered.

On the other hand, the analysis of both periods, whose intersection is not empty, revealed different associations between the common rain gauge stations. At a 0.05 significance level, the independence was only rejected in both periods for the pairs $B-G, G-I$, and $\mathrm{I}-\mathrm{L}$. It was also observed more pairs of associated stations in Period 1, that begins later, which can be an indicator of changes in Madeira's extreme rainfall dependence with time. The analysis corresponding to Period 1 led to four groups of three pairwise associated stations, which were not observed in Period 2. A better coverage of Madeira Island in this period, naturally obtained by an increase of the number of rain gauge stations, allowed the observation of other different 17 groups of three pairwise associated stations. Among these, a group of a particular interest is the already mentioned group formed by Santana (I), Funchal (K) and Lugar de Baixo (L), the only group solely formed by common stations to both periods observed, in Period 2, that was not found in the analysis of Period 1.

In summary, the analysis made in this work highlights the challenge of finding a model to characterize spatial extreme rainfall in Madeira, an island with a highly rugged topography. The motivation for this work came from the lack of information about Madeira's extreme rainfall dependence that can be used to support the construction of such a model. The apparent signs of the existence of a change over time in the dependence of rainfall extremes and the identified groups of three pairwise associated stations provide an interesting starting point for searching for the best approach to Madeira's spatial extreme rainfall characterization.

\section{Acknowledgements}

The authors wish to thank the Portuguese Foundation for Science and Technology (FCT) for the financial support through the PhD grant SFRH/BD/39226/2007, financed by national funds of MCTES. They are also grateful to the Center of Statistics and Applications of the University of Lisbon (CEAUL) for the bibliographical and financial support through the FCT under the projects PEstOE/MAT/UI0006/2011 and PEst-OE/MAT/UI0006/2014, and to the University of Madeira for the logistic support. The authors wish also to thank the Portuguese Institute for Sea and Atmosphere and namely to Dr. Victor Prior, and the Department of Hydraulics and Energy Technologies of the Madeira Regional Laboratory of Civil Engineering and namely to Dr. Carlos Magro, for providing the rainfall data used in this study. The second author also thanks the Brazilian agency CAPES for the partial financial support during his sabbatical leave.

\section{Appendix A. Supplementary data}

Supplementary data related to this article can be found at http:// dx.doi.org/10.1016/j.pce.2015.11.006.

\section{References}

Baioni, D., 2011. Human activity and damaging landslides and floods on Madeira Island. Nat. Hazards Earth Syst. Sci. 11, 3035-3046.

Couto, F.T., Salgado, R., Costa, M.J., 2012. Analysis of intense rainfall events on Madeira Island during the 2009/2010 winter. Nat. Hazards Earth Syst. Sci. 12, 2225-2240.

Davison, A.C., Padoan, S.A., Ribatet, M., 2012. Statistical modeling of spatial extremes. Stat. Sci. 27, 161-186.

Fragoso, M., Trigo, R.M., Pinto, J.G., Lopes, S., Lopes, A., Ulbrich, S., Magro, C., 2012. The 20 February 2010 Madeira flash-floods: synoptic analysis and extreme rainfall assessment. Nat. Hazards Earth Syst. Sci. 12, 715-730.

Genest, C., Favre, A.C., 2007. Everything you always wanted to know about copula modeling but were afraid to ask. J. Hydrol. Eng. 12, 347-368.

Gorricha, J., Lobo, V., Costa, A.C., 2012. Spatial characterization of extreme precipitation in Madeira Island using geostatistical procedures and a 3D SOM. In: Fourth International Conference on Advanced Geographic Information Systems, Applications, and Services. IARIA, Valencia, Spain, pp. 98-104.

Hayward, D., Clarke, R.T., 1996. Relationship between rainfall, altitude and distance from the sea in the Freetown Peninsula, Sierra Leone. Hydrol. Sci. J. 41, 377-384.

Hong, Y., Adler, R.F., Negri, A., Huffman, G.J., 2007. Flood and landslide applications of near real-time satellite rainfall products. Nat. Hazards 43, 285-294.

Hu, K., Li, Y., Wei, F., 2009. Annual risk assessment on high-frequency debris-flow fans. Nat. Hazards 49, 469-477.

Hürlimann, M., Copons, R., Altimir, J., 2006. Detailed debris flow hazard assessment in Andorra: a multidisciplinary approach. Geomorphology 78, 359-372.

Kalvoda, J., Rosenfeld, C.L. (Eds.), 1998. Geomorphological Hazards in High Mountain Areas. Kluwer, Dordrecht.

Kanji, M.A., Cruz, P.T., Massad, F., 2008. Debris flow affecting the Cubatão Oil Refinery, Brazil. Landslides 5, 71-82.

Koutsoyiannis, D., 2004. Statistics of extremes and estimation of extreme rainfall: I, Theoretical investigation. Hydrol. Sci. J. 49, 575-590.

Konrad II, C.E., 1996. Relationships between precipitation event types and topography in the southern Blue Ridge Mountains of the southeastern USA. Int. J. Climatol. 16, 49-62.

Lima, M.I.P., Lima, J.L.M.P., 2009. Investigating the multifractality of point precipitation in the Madeira archipelago. Nonlinear Process. Geophys. 16, 299-311.

Nelsen, R.B., 2002. Concordance and copulas: a survey. In: Cuadras, C.M., Fortiana, J., Rodríguez-Lallena, J.A. (Eds.), Distributions with Given Marginals and Statistical Modelling. Kluwer, Dordrecht, pp. 169-177.

Nelsen, R.B., 2006. An Introduction to Copulas, second ed. Springer, New York.

Prada, S., Sequeira, M.M., Figueira, C., Silva, M.O., 2009. Fog precipitation and rainfall interception in the natural forests of Madeira Island (Portugal). Agric. For. Meteorol. 149, 1179-1187.

Quintal, R., 1999. Aluviões da Madeira; Séculos XIX e XX. Territorium 6, 31-48.

R Development Core Team, 2011. R: a Language and Environment for Statistical Computing. R Foundation for Statistical Computing, Vienna, Austria.

Rodrigues, D., Ayala-Caicedo, F.J., 2003. Rain induced landslides and debris flows in Madeira Island, Portugal. Landslide News. Jpn. Landslide Soc. 14-15, 43-45.

Salvadori, G., Michele, C.D., Kottegoda, N.T., Rosso, R., 2007. Extremes in Nature: an Approach Using Copulas. Springer, Dordrecht.

Schweizer, B., Wolf, E.F., 1981. On nonparametric measures of dependence for random variables. Ann. Statistics 9, 879-885.

Shahin, M., 2012. Hydrology and water resources of African islands. In: Hydrology and Water Resources of Africa. Kluwer, Dordrecht, pp. 565-582.

Sklar, A., 1959. Fonctions de répartition à $n$ dimensions et leurs marges. Publ. l'Institut Stat. l'Université Paris 8, 229-231.

Spreafico, M., 2006. Flash floods in mountain areas. In: Demuth, S., Gustard, A., Planos, E., Seatena, F., Servat, E. (Eds.), Climate Variability and Change: Hydrological Impacts. IAHS Press, Wallingford, UK, pp. 232-238.

Sziemer, P., 2000. Madeira's Natural History in a Nutshell. Francisco Ribeiro \& Filhos, Funchal, Portugal.

Wilford, D.J., Sakals, M.E., Innes, J.L., Sidle, R.C., Bergerud, W.A., 2004. Recognition of debris flow, debris flood and flood hazard through watershed morphometrics. Landslides 1, 61-66.

Woo, M.-K., Jones, J.A.A., 2002. Coping with hydrological extremes. Mitig. Adapt. Strategies Glob. Change 7, 201-202. 